\title{
Experimental and Computational Studies of the Kinetics of the Reaction of Atomic Hydrogen with Methanethiol
}

\author{
Katherine E. Kerr, Ionut M. Alecu, Kristopher M. Thompson, Yide Gao, and Paul Marshall* \\ Department of Chemistry and Center for Advanced Scientific Computing and Modeling, University of North Texas, 1155 Union \\ Circle \#305070, Denton, Texas 76203-5017, United States
}

\section{Supporting Information}

ABSTRACT: The overall rate constant for $\mathrm{H}+\mathrm{CH}_{3} \mathrm{SH}$ has been studied over 296$1007 \mathrm{~K}$ in an Ar bath gas using the laser flash photolysis method at $193 \mathrm{~nm} . \mathrm{H}$ atoms were generated from $\mathrm{CH}_{3} \mathrm{SH}$ and in some cases $\mathrm{NH}_{3}$. They were detected via timeresolved resonance fluorescence. The results are summarized as $k=(3.45 \pm 0.19) \times$ $10^{-11} \mathrm{~cm}^{3}$ molecule $\mathrm{s}^{-1} \exp \left(-6.92 \pm 0.16 \mathrm{~kJ} \mathrm{~mol}^{-1} / \mathrm{RT}\right)$ where the errors in the Arrhenius parameters are the statistical uncertainties at the $2 \sigma$ level. Overall error limits of $\pm 9 \%$ for $k$ are proposed. In the overlapping temperature range there is very good agreement with the resonance fluorescence measurements of Wine et al. Ab initio data and transition state theory yield moderate accord with the total rate constant, but not with prior mass spectrometry measurements of the main product channels leading to $\mathrm{CH}_{3} \mathrm{~S}+\mathrm{H}_{2}$ and $\mathrm{CH}_{3}+\mathrm{H}_{2} \mathrm{~S}$ by Amano et al.

\section{INTRODUCTION}

Organosulfur compounds contribute to the chemistry of a number of systems, including emissions from plankton into the atmosphere, ${ }^{1}$ the Claus process for removing sulfur from hydrocarbon fuels, ${ }^{2}$ and chemical vapor deposition of diamond films. ${ }^{3}$ Here we focus on one of the simplest compounds, methanethiol, and its bimolecular reaction with atomic hydrogen

$$
\mathrm{H}+\mathrm{CH}_{3} \mathrm{SH} \stackrel{k}{\rightarrow} \text { products }
$$

The total $\mathrm{H}$ atom removal rate constant $k$ has been studied before, most notably by Wine et al. ${ }^{4}$ over $247-405 \mathrm{~K}$ at total bath gas pressures in the range $50-76$ Torr $(1$ Torr $\approx 1.33 \mathrm{mbar}$ ) using the resonance fluorescence flash photolysis technique with $248 \mathrm{~nm}$ laser pulses, and by Amano et al. ${ }^{5}$ over $313-454 \mathrm{~K}$ at pressures between 250 and 290 Torr using an electron beam and mass spectrometry. The previous work has found the reaction to be second-order, with no pressure dependence observed over the narrow ranges studied. Rate constants from the two studies do not agree and, as will be seen, our experiments support those of Wine et al. The reaction has also been studied at room temperature. $^{6-9}$ One aim of the present work is to increase the temperature range to beyond $1000 \mathrm{~K}$, which results in data now being available over a factor of 4 range in temperature. These data prove challenging to model theoretically, in part because the properties of the dominant transition state are constrained by comparison with experiment over a wide range of collision energies.

An intriguing aspect of this reaction is that there are several thermochemically plausible channels. These include $\mathrm{H}$ atom abstraction from the $\mathrm{SH}$ group (R1.1), $\mathrm{H}$ atom abstraction from the $\mathrm{CH}_{3}$ group (R1.2), breaking the $\mathrm{C}-\mathrm{S}$ bond and displacing the $\mathrm{CH}_{3}$ group (R1.3), and cleavage of the $\mathrm{C}-\mathrm{S}$ bond and displacing the $\mathrm{SH}$ group (R1.4):

$$
\begin{aligned}
& \mathrm{H}+\mathrm{CH}_{3} \mathrm{SH} \stackrel{k_{1}}{\rightarrow} \mathrm{H}_{2}+\mathrm{CH}_{3} \mathrm{~S} \\
& \mathrm{H}+\mathrm{CH}_{3} \mathrm{SH} \stackrel{k_{2}}{\rightarrow} \mathrm{H}_{2}+\mathrm{CH}_{2} \mathrm{SH} \\
& \mathrm{H}+\mathrm{CH}_{3} \mathrm{SH} \stackrel{k_{3}}{\rightarrow} \mathrm{H}_{2} \mathrm{~S}+\mathrm{CH}_{3} \\
& \mathrm{H}+\mathrm{CH}_{3} \mathrm{SH} \stackrel{k_{4}}{\rightarrow} \mathrm{SH}+\mathrm{CH}_{4}
\end{aligned}
$$

The thermochemistry of these pathways is summarized in Table 1. High-accuracy enthalpies of formation are available for $\mathrm{H}$, $\mathrm{CH}_{3}$, and $\mathrm{CH}_{4}$ from the Active Thermochemical Tables ${ }^{10}$ and for $\mathrm{H}_{2} \mathrm{~S}, \mathrm{CH}_{3} \mathrm{SH}$, and $\mathrm{CH}_{3} \mathrm{~S}$ from the NIST Computational

Table 1. Thermochemistry and Barrier Heights of Possible Reaction Channels for the $\mathrm{H}+\mathrm{CH}_{3} \mathrm{SH}$ Reaction at $\mathbf{0 ~ K}$

$\begin{array}{cccc}\begin{array}{c}\text { product } \\ \text { channel }\end{array} & \begin{array}{c}\text { experimental } \\ \mathrm{kJ} \mathrm{mol}^{-1} \mathrm{a}_{\mathrm{r}} \mathrm{H}_{0} /\end{array} & \begin{array}{c}\text { computed } \Delta_{b} H_{0} / \mathrm{kJ} \\ \mathrm{mol}^{-1} b\end{array} & \begin{array}{c}\text { computed } \mathrm{E}_{0}^{\ddagger} \\ \mathrm{mol}^{-1} b^{\ddagger}\end{array} \\ \begin{array}{c}\mathrm{H}_{2}+\mathrm{CH}_{3} \mathrm{~S} \\ (1)\end{array} & -74.29 & -73.33 & 8.17 \\ \mathrm{H}_{2}+\mathrm{CH}_{2} \mathrm{SH} & & -39.71 & 36.91 \\ (2) & & -72.80 & 14.40 \\ \mathrm{H}_{2} \mathrm{~S}+\mathrm{CH}_{3} & -71.95 & -128.86 & 81.09 \\ (3) & -128.12 & & \\ \begin{array}{l}\mathrm{SH}+\mathrm{CH}_{4} \\ (4)\end{array} & & & \end{array}$

${ }^{a}$ See text. ${ }^{b}$ Via a modified W1 method (see text).

Special Issue: 100 Years of Combustion Kinetics at Argonne: A Festschrift for Lawrence B. Harding, Joe V. Michael, and Albert F. Wagner

Received: December 29, 2014

Revised: April 13, 2015

Published: April 14, 2015 
Chemistry Comparison and Benchmark Database, ${ }^{11}$ and we have previously recommended thermochemistry for $\mathrm{SH}^{12}$ Another aim of the work is to investigate the product branching ratios by computational methods. There has been an initial theoretical study of three of these channels by Wang et al., who employed G3(MP2) energies and deduced that channel R1.1 was the major pathway. ${ }^{13}$ Channel R1.4, which is the most exothermic pathway, has not been considered previously. Here we modify the W1U algorithm of Martin and co-workers ${ }^{14}$ to investigate the transition states and derive the rate constants $k_{1}-k_{4}$. We also make a detailed analysis of the roles of anharmonicity in the reactants and transition states. Our theoretical data are compared to the measurements of channels R1.1 and R1.3 by Amano et al. as well as the present measurements, and the Wine et al. results for the total rate constant $k=\Sigma k_{i}$. Theoretical expressions for $k_{1}-$ $k_{4}$ are derived for temperatures up to $3000 \mathrm{~K}$. Although $\mathrm{CH}_{3} \mathrm{SH}$ will be short-lived at high temperatures, these expressions combined with the known equilibrium constants will assist modeling of sulfur systems via the reverse of processes $\mathrm{R} 1.1-\mathrm{R} 1.4$, in analysis of situations where reactions of species such as $\mathrm{SH}$ and $\mathrm{CH}_{3} \mathrm{~S}$ are relevant, for example, $\mathrm{CS}_{2}$ formation in the Claus process ${ }^{15}$ and the oxidation of $\mathrm{H}_{2} \mathrm{~S} / \mathrm{CH}_{4}$ mixtures in the combustion of sour gas. 16,17

\section{EXPERIMENTAL METHODOLOGY}

We applied the flash photolysis/resonance fluorescence method. Our apparatus and its operation have been described elsewhere, ${ }^{18-20}$ including modifications for studying atomic hydrogen. $^{21,22}$ Here the hydrogen atoms were generated by pulsed excimer laser photolysis of precursor molecules at a wavelength of $193 \mathrm{~nm}$. Slow flows of the precursors were diluted in a large excess of inert Ar bath gas to maintain isothermal conditions, monitored with a retractable thermocouple corrected for radiation errors, and to slow diffusion of radicals to the walls of the reactor. Methanethiol itself can photolyze via two pathways, breaking either the $\mathrm{S}-\mathrm{H}$ bond or the $\mathrm{C}-\mathrm{S}$ bond:

$$
\begin{aligned}
& \mathrm{CH}_{3} \mathrm{SH}+h \nu \rightarrow \mathrm{CH}_{3} \mathrm{~S}+\mathrm{H} \\
& \mathrm{CH}_{3} \mathrm{SH}+h \nu \rightarrow \mathrm{CH}_{3}+\mathrm{SH}
\end{aligned}
$$

The bond dissociation energies have been measured as $385 \pm 4$ $\mathrm{kJ} \mathrm{mol}^{-1}$ for the $\mathrm{S}-\mathrm{H}$ bond and $314 \pm 6 \mathrm{~kJ} \mathrm{~mol}^{-1}$ for the $\mathrm{C}-\mathrm{S}$ bond. ${ }^{23}$ The branching to the second pathway was measured to be $7 \%$ by Bridges and White at $248 \mathrm{~nm}$ and is more significant at shorter wavelengths. ${ }^{24}$ At lower temperatures we used photolysis of a small fraction of the methanethiol reactant itself as the hydrogen source, with photolysis energies kept low to minimize the initial radical concentrations. At higher temperatures it became difficult to generate enough $\mathrm{H}$ atoms to observe the reaction without causing excessive secondary chemistry. Ammonia was used instead, and the reaction was checked at lower temperatures to verify agreement with the methanethiolsourced points. Ammonia has a larger absorption cross section at $193 \mathrm{~nm}$ than methanethiol. Initial photolytic $\mathrm{H}$ atom concentrations were estimated separately from the laser pulse energy, $E$, the cross-sectional area of the laser beam of $0.50 \mathrm{~cm}^{2}$ and the absorption cross-section, $\sigma$, which is $5.0 \times 10^{-18} \mathrm{~cm}^{2}$ for ammonia $^{25}$ and $1.86 \times 10^{-18} \mathrm{~cm}^{2}$ for $\mathrm{CH}_{3} \mathrm{SH}^{26}$ The quantum yield of $\mathrm{H}$ from ammonia is taken to be 1 , and to be 0.55 for $\mathrm{CH}_{3} \mathrm{SH}^{26}$

Resonance fluorescence was excited by a microwave plasma in a flowing sample of diluted $\mathrm{H}_{2}$, which generated Lyman $\alpha$ radiation at $122 \mathrm{~nm}$. Magnesium fluoride optics were employed, and a dry air filter helped isolate the Lyman $\alpha$ wavelength from other atomic lines which might be present. Fluorescence signals were captured with a solar blind photomultiplier tube and processed through a pulse discriminator, and photon counts as a function of time were accumulated for typically several hundred decays (repeated at $\sim 1 \mathrm{~Hz}$ ) in a multichannel scaler.

Once formed, $\mathrm{H}$ atoms are removed through two main pathways, reaction $\mathrm{R} 1$ and diffusion out of the observation zone, which is described by an effectively first-order rate constant $k_{\text {diff. }}$. The corresponding rate expression is

$$
\frac{\mathrm{d}[\mathrm{H}]}{\mathrm{dt}}=-k[\mathrm{H}]\left[\mathrm{CH}_{3} \mathrm{SH}\right]-k_{\mathrm{diff}}[\mathrm{H}]=-k_{\mathrm{ps} 1}[\mathrm{H}]
$$

We employed $\left[\mathrm{CH}_{3} \mathrm{SH}\right] \gg[\mathrm{H}]$, so the change in $\left[\mathrm{CH}_{3} \mathrm{SH}\right]$ will be negligible over the course of the reaction. Under these pseudo-first-order conditions $k_{\mathrm{ps} 1}$ is the pseudo-first-order rate constant. We therefore expect $[\mathrm{H}]$ to decay exponentially. The observed hydrogen atom fluorescence signal $I_{\mathrm{f}}$ was fit to a singleexponential function of time $t$, where $A$ and $B$ are constants:

$$
I_{\mathrm{f}}=A \mathrm{e}^{-k_{\mathrm{ps}^{1}}}+B
$$

The constant $B$ accounts for a constant background in the signal, caused primarily by constant scattered light from the resonance lamp. An example time profile of $I_{\mathrm{f}}$ is shown as the inset in Figure 1. The exponential decays are fitted with a nonlinear least-

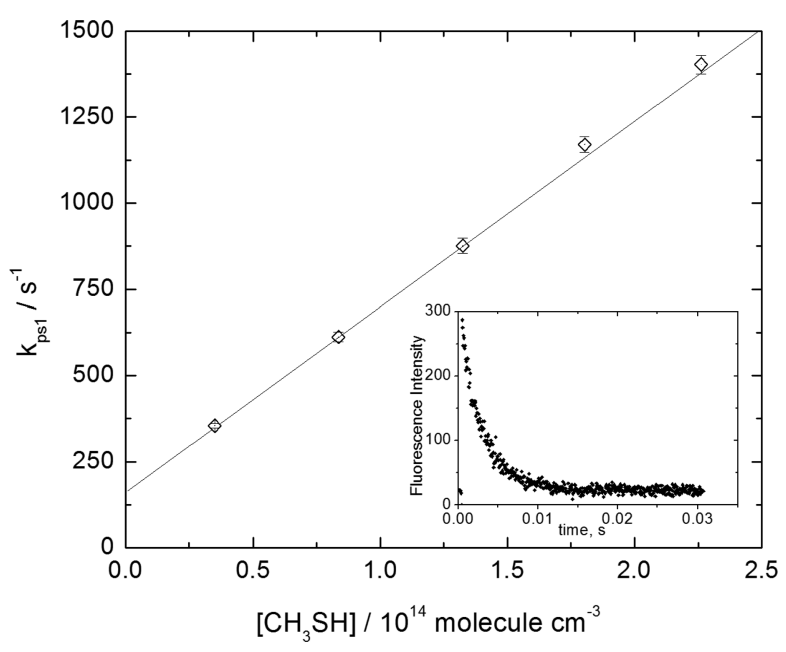

Figure 1. Determination of the second-order rate constant $k$ by plotting $k_{\mathrm{ps} 1}$ with $2 \sigma$ error bars obtained from each pseudo-first-order decay against $\left[\mathrm{CH}_{3} \mathrm{SH}\right]$. The inset shows the decay from the first $k_{\mathrm{ps} 1}$ point. In this experiment, at $450 \mathrm{~K}$ and $67 \mathrm{mbar}, \mathrm{CH}_{3} \mathrm{SH}$ was the only hydrogen atom source.

squares fitting algorithm that yields $k_{\mathrm{ps} 1}$ and its statistical error. ${ }^{27,28}$ Variation of $\left[\mathrm{CH}_{3} \mathrm{SH}\right]$ allows $k$ to be separated from diffusion effects, and $k$ is obtained as the slope of plots of $k_{\mathrm{ps} 1}$ vs $\left[\mathrm{CH}_{3} \mathrm{SH}\right]$ like that shown in Figure 1 . Weighted linear leastsquares fits to the $k_{\mathrm{ps} 1}$ vs $\left[\mathrm{CH}_{3} \mathrm{SH}\right]$ plots, which take into account the horizontal and vertical error bars, are used to determine the second-order rate constant $k$, along with its statistical $1 \sigma$ error.

\section{EXPERIMENTAL RESULTS}

Table 2 summarizes 35 determinations of $k$, each from five different methanethiol concentrations, with the largest value tabulated. Apart from changing the temperature $T$, we emphasized variation of the experimental parameters $\tau$, the average residence time inside the heated reactor before 
Table 2. Experimental Conditions and Measured Rate Constants $k$ for the $\mathrm{H}+\mathrm{CH}_{3} \mathrm{SH}$ Reaction

\begin{tabular}{|c|c|c|c|c|c|c|c|c|}
\hline$T / \mathrm{K}$ & $\tau / \mathrm{s}$ & $\begin{array}{l}\mathrm{F} / \mathrm{mJ} \\
\mathrm{cm}^{-2}\end{array}$ & $\underset{\mathrm{mbar}}{p /}$ & $\begin{array}{c}{\left[\mathrm{CH}_{3} \mathrm{SH}\right]_{\max } / 10^{14} \mathrm{~cm}^{-3}} \\
\text { molecule }\end{array}$ & $\begin{array}{c}{\left[\mathrm{NH}_{3}\right] / 10^{14} \mathrm{~cm}^{-3}} \\
\text { molecule }\end{array}$ & $\begin{array}{c}k / 10^{-12} \mathrm{~cm}^{3} \\
\text { molecule }^{-1} \mathrm{~s}^{-1}\end{array}$ & $\begin{array}{c}{[\mathrm{H}]_{0, \max } / 10^{11} \mathrm{~cm}^{-3}} \\
\text { molecule }\end{array}$ & $\begin{array}{c}{[\mathrm{Ar}] / 10^{17} \mathrm{~cm}^{-3}} \\
\text { molecule }\end{array}$ \\
\hline 290 & 1.5 & 0.34 & 26.7 & 15.2 & 0 & $1.83 \pm 0.16$ & 5.1 & 6.6 \\
\hline 295 & 3.7 & 1.49 & 66.7 & 14.7 & 0 & $1.83 \pm 0.27$ & 22 & 16.3 \\
\hline 295 & 3.7 & 0.99 & 66.5 & 14.7 & 0 & $1.81 \pm 0.15$ & 14 & 16.3 \\
\hline 296 & 2.9 & 1.14 & 133.5 & 17.6 & 0 & $2.15 \pm 0.10$ & 20 & 32.7 \\
\hline 296 & 3.7 & 2.42 & 66.8 & 11.0 & 0 & $1.97 \pm 0.09$ & 26 & 16.4 \\
\hline 296 & 1.3 & 0.45 & 69.1 & 2.1 & 4.0 & $2.12 \pm 0.06$ & 9.7 & 16.9 \\
\hline 296 & 1.3 & 0.22 & 69.1 & 2.1 & 4.0 & $2.04 \pm 0.06$ & 4.7 & 16.9 \\
\hline 299 & 1.2 & 0.20 & 68.1 & 2.3 & 3.8 & $2.22 \pm 0.09$ & 4.1 & 16.5 \\
\hline 299 & 1.2 & 0.09 & 68.1 & 2.3 & 3.8 & $2.15 \pm 0.09$ & 1.9 & 16.5 \\
\hline 447 & 1.2 & 1.58 & 66.5 & 1.5 & 0 & $5.79 \pm 0.28$ & 2.4 & 10.8 \\
\hline 448 & 2.5 & 3.50 & 66.7 & 4.7 & 0 & $5.97 \pm 0.38$ & 16 & 10.8 \\
\hline 449 & 2.5 & 2.08 & 66.7 & 3.5 & 0 & $5.38 \pm 0.07$ & 7.2 & 10.7 \\
\hline 449 & 2.5 & 1.34 & 66.7 & 3.5 & 0 & $5.34 \pm 0.05$ & 4.7 & 10.7 \\
\hline 449 & 2.5 & 0.65 & 66.7 & 3.5 & 0 & $5.31 \pm 0.34$ & 2.3 & 10.7 \\
\hline 600 & 0.4 & 0.08 & 65.7 & 1.1 & 5.4 & $10.3 \pm 0.39$ & 2.3 & 7.9 \\
\hline 601 & 0.7 & 0.30 & 26.7 & 1.4 & 4.4 & $8.34 \pm 0.33$ & 6.8 & 3.2 \\
\hline 601 & 0.7 & 0.09 & 26.7 & 1.4 & 4.4 & $7.11 \pm 0.25$ & 2.2 & 3.2 \\
\hline 601 & 0.9 & 0.09 & 66.7 & 1.6 & 1.7 & $8.57 \pm 0.17$ & 0.93 & 8.0 \\
\hline 601 & 0.9 & 0.05 & 66.7 & 1.6 & 1.7 & $8.84 \pm 0.49$ & 0.45 & 8.0 \\
\hline 605 & 0.7 & 0.03 & 26.7 & 0.8 & 1.7 & $7.23 \pm 0.61$ & 0.29 & 3.2 \\
\hline 605 & 0.7 & 0.07 & 26.7 & 0.8 & 1.7 & $7.39 \pm 0.57$ & 0.68 & 3.2 \\
\hline 605 & 0.4 & 0.08 & 27.9 & 1.0 & 3.9 & $10.5 \pm 0.31$ & 1.6 & 3.3 \\
\hline 795 & 0.7 & 0.12 & 66.4 & 2.0 & 9.9 & $11.2 \pm 0.8$ & 6.0 & 6.0 \\
\hline 795 & 0.7 & 0.07 & 66.4 & 2.0 & 9.9 & $11.1 \pm 0.5$ & 3.7 & 6.0 \\
\hline 797 & 0.1 & 0.44 & 13.6 & 0.9 & 2.0 & $11.7 \pm 1.1$ & 4.7 & 1.2 \\
\hline 800 & 0.3 & 0.32 & 27.7 & 1.0 & 2.5 & $11.0 \pm 0.7$ & 4.2 & 2.5 \\
\hline 801 & 0.3 & 0.30 & 30.1 & 1.8 & 2.5 & $10.2 \pm 1.5$ & 4.1 & 2.7 \\
\hline 802 & 0.3 & 0.29 & 14.1 & 1.0 & 2.8 & $11.3 \pm 0.8$ & 4.3 & 1.3 \\
\hline 806 & 0.3 & 0.52 & 27.3 & 1.3 & 2.6 & $12.7 \pm 0.4$ & 7.2 & 2.5 \\
\hline 806 & 0.3 & 0.22 & 27.3 & 1.3 & 2.6 & $12.2 \pm 0.7$ & 3.1 & 2.5 \\
\hline 806 & 0.7 & 0.13 & 70.3 & 0.8 & 11.0 & $10.6 \pm 1.6$ & 7.2 & 6.3 \\
\hline 806 & 0.7 & 0.06 & 70.3 & 0.8 & 11.0 & $10.6 \pm 0.7$ & 3.5 & 6.3 \\
\hline 1002 & 0.08 & 0.07 & 15.7 & 0.6 & 2.4 & $17.0 \pm 1.4$ & 0.88 & 1.1 \\
\hline 1005 & 0.15 & 0.08 & 13.5 & 0.5 & 3.0 & $16.4 \pm 1.5$ & 1.2 & 1.0 \\
\hline 1014 & 0.11 & 0.08 & 13.9 & 0.3 & 3.0 & $16.1 \pm 2.0$ & 1.2 & 1.0 \\
\hline
\end{tabular}

photolysis, and the total pressure $p$, which check for good mixing and the lack of thermal decomposition within the reactor. The laser fluence $F$ and the precursor concentrations control the initial radical concentrations and were adjusted to ensure that exponential decays of $[\mathrm{H}]$ were seen. The maximum estimated initial $\mathrm{H}$ atom concentration of course increases along with $\left[\mathrm{CH}_{3} \mathrm{SH}\right]$. In this regime no systematic variation of $k$ with the experimental parameters was noted, so that reaction Rl appears to have been isolated from secondary chemistry involving photolysis or reaction products.

The data are plotted in Arrhenius form in Figure 2 and may be summarized over $296-1007 \mathrm{~K}$ as

$$
\begin{aligned}
k= & (3.45 \pm 0.19) \times 10^{-11} \mathrm{~cm}^{3} \text { molecule } \mathrm{s}^{-1} \\
& \times \exp \left(-6.92 \pm 0.16 \mathrm{kJmol}^{-1} / R T\right)
\end{aligned}
$$

where the errors in the Arrhenius parameters are the statistical uncertainties at the $2 \sigma$ level. Bearing in mind possible systematic errors, we propose overall error limits of $\pm 9 \%$ in $k$.

Our measurements agree very well with those of Wine et al. ${ }^{4}$ in the overlapping temperature region, as shown in Figure 2, as do their reported Arrhenius parameters of $(3.45 \pm 0.14) \times 10^{-11}$ $\mathrm{cm}^{3}$ molecule $\mathrm{s}^{-1} \mathrm{~s}^{-1}$ and $7.03 \pm 0.07 \mathrm{~kJ} \mathrm{~mol}^{-1}$. Comparison with the total rate constant from Amano et al. ${ }^{5}$ indicates agreement

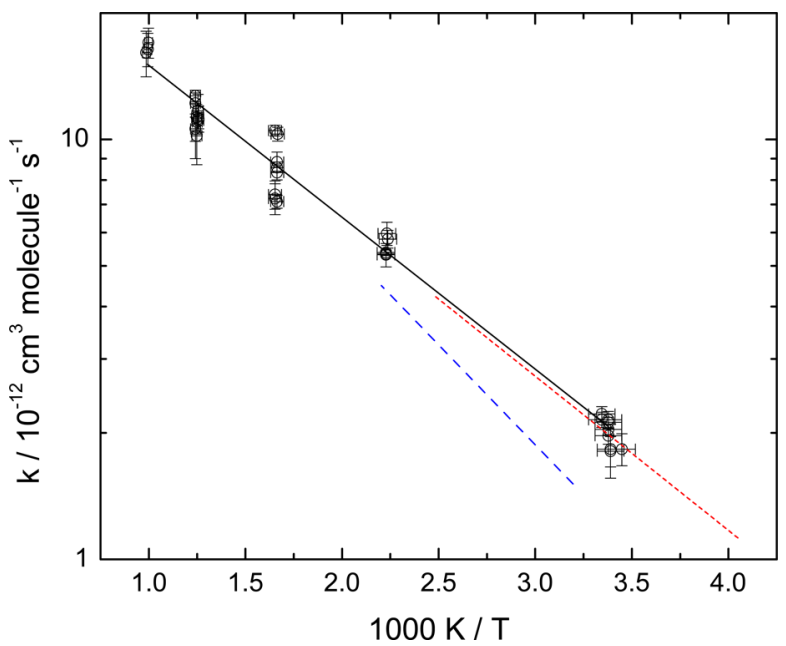

Figure 2. Arrhenius plot of the present measurements for the total $\mathrm{H}+$ $\mathrm{CH}_{3} \mathrm{SH}$ rate constant, with $1 \sigma$ error bars in $k$ and T. Also shown is previous work by Wine et al., ${ }^{4}$ short red dashes, and Amano et al., ${ }^{5}$ blue dashes.

only to within a factor of 2-3, a larger deviation than expected from the statistical uncertainties alone. In units of $10^{-12} \mathrm{~cm}^{3}$ 


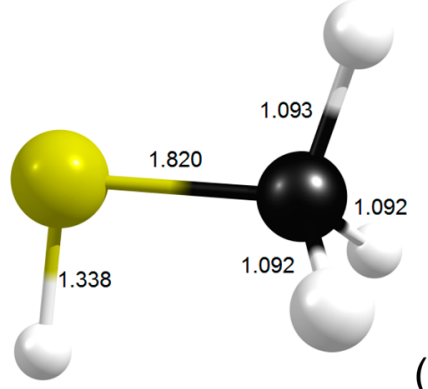

(a)
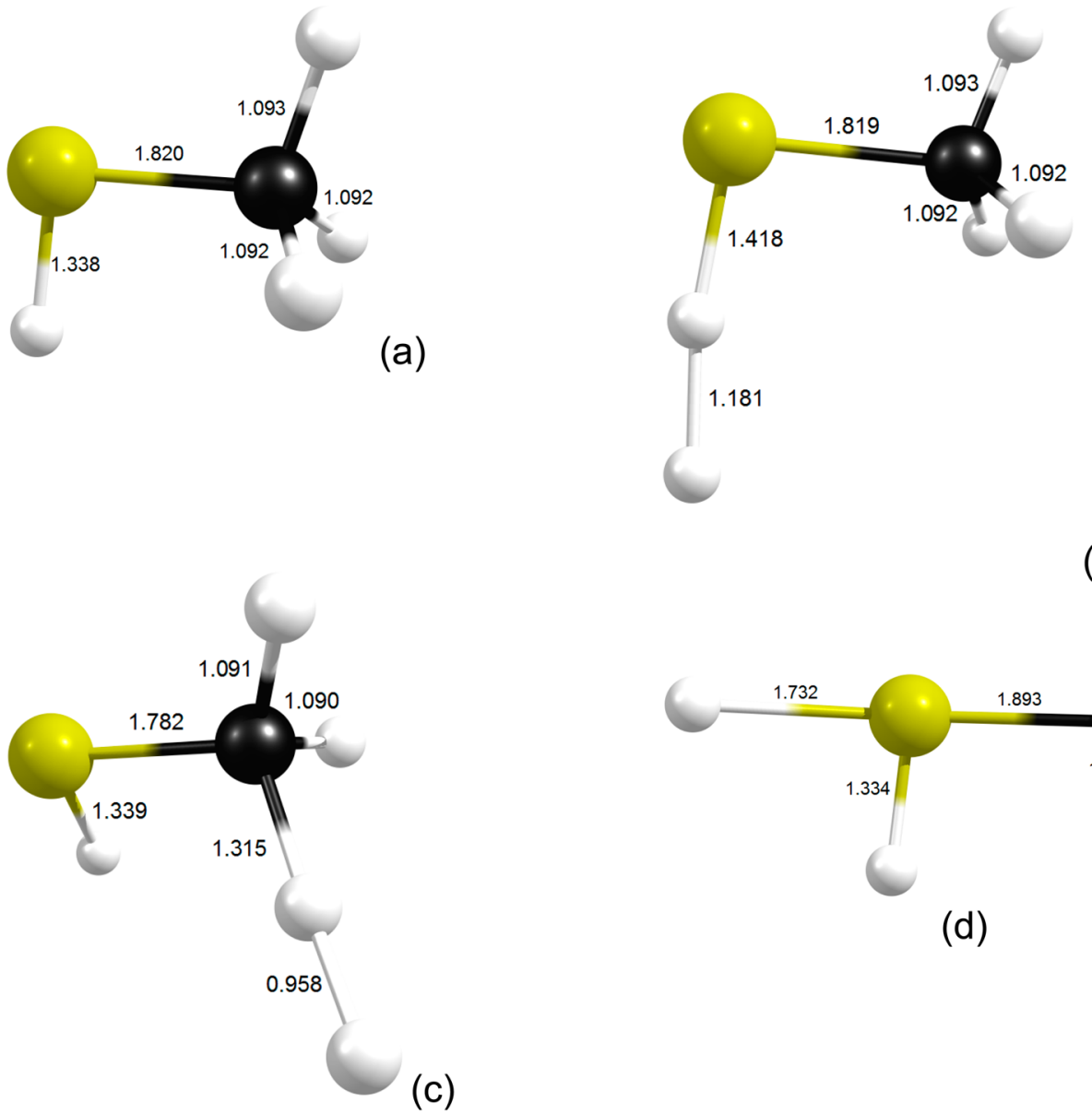

(b)

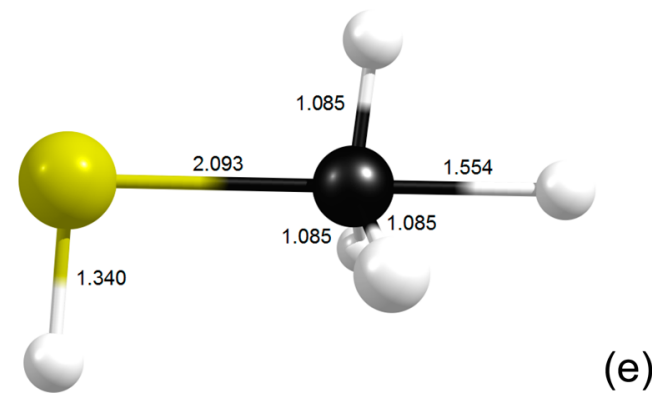

Figure 3. Structures derived with QCISD/6-311G(d,p) theory for (a) methanethiol and (b)-(e) transition states TS1-4 for its reactions with hydrogen atoms via pathways R1.1-R1.4.

molecule ${ }^{-1} \mathrm{~s}^{-1}$, at room temperature Vaghjiani et al. ${ }^{6}$ and Martin et al. ${ }^{7}$ found $k$ equal to $2.13 \pm 0.31$ and $2.19 \pm 0.20$ whereas we obtain $2.11 \pm 0.18$. Balla and Heicklen ${ }^{8,9}$ derived values of $k_{1}$ for channel R1.1 of around $4.07 \times 10^{-13}$ and $1.79 \times 10^{-12} \mathrm{~cm}^{3}$ molecule ${ }^{-1} \mathrm{~s}^{-1}$ by fitting to complex mechanisms involving $\mathrm{H}+$ $\mathrm{NO}$ and $\mathrm{H}+\mathrm{O}_{2}$, respectively. The latter value appears to be more accurate. Overall, our results agree with most of the prior measurements and extend the temperature range to over $1000 \mathrm{~K}$.

\section{COMPUTATIONAL ANALYSIS}

4.1. Potential Energy Diagram. $A b$ initio methods were applied to the stationary points of the $\mathrm{H}+\mathrm{CH}_{3} \mathrm{SH}$ reaction. The geometries and vibrational frequencies (the latter scaled by a standard factor of $0.954^{11}$ ) were obtained using QCISD/6$311 G(d, p)$ theory. ${ }^{29,30}$ This scaling factor accounts for the typically modest anharmonicity in most vibrations, so that the computed harmonic frequencies are scaled to match observed $\mathrm{v}=$ $0 \rightarrow \mathrm{v}=1$ fundamental transitions. A more detailed approach is outlined below for certain highly anharmonic normal modes. These QCISD geometries are used for single-point energies derived via the W1U methodology of Martin and co-workers, ${ }^{14}$ to yield coupled cluster energies $\operatorname{CCSD}(\mathrm{T})$ extrapolated to the infinite basis set limit along with corrections for core electron correlation and scalar relativistic effects. This is a modification of the original $\mathrm{W} 1 \mathrm{U}$ method, which was based on density functional theory for the geometry and frequencies. The absolute energies obtained in this way are summarized in the Supporting Information (Table S1). These $a b$ initio calculations were made with the GAUSSIAN 09 program suite. ${ }^{31}$ An empirical correction of $-2.255 \mathrm{~kJ} \mathrm{~mol}^{-1}$ is applied to the energy of the $\mathrm{SH}$ radical to account for the spin-orbit splitting of its ${ }^{2} \Pi$ state. ${ }^{11}$ The corresponding reaction enthalpies are compared with 
experiment in Table 1, and the accord is seen to be very good, with a root-mean-square deviation of only $0.9 \mathrm{~kJ} \mathrm{~mol}^{-1}$. This same level of theory was applied to the transition states (TSs) of reactions R1.1-R1.4 which are illustrated in Figure 3. The complete geometries and other details are provided in the Supporting Information (Table S2). The resulting barrier heights at $0 \mathrm{~K}$, including zero-point vibrational energy, are listed in Table 1 and the four reaction pathways are sketched in the potential energy diagram of Figure 4. It may be seen that the thermochemistry of the different pathways is an incomplete guide to the ordering of the energy barriers.

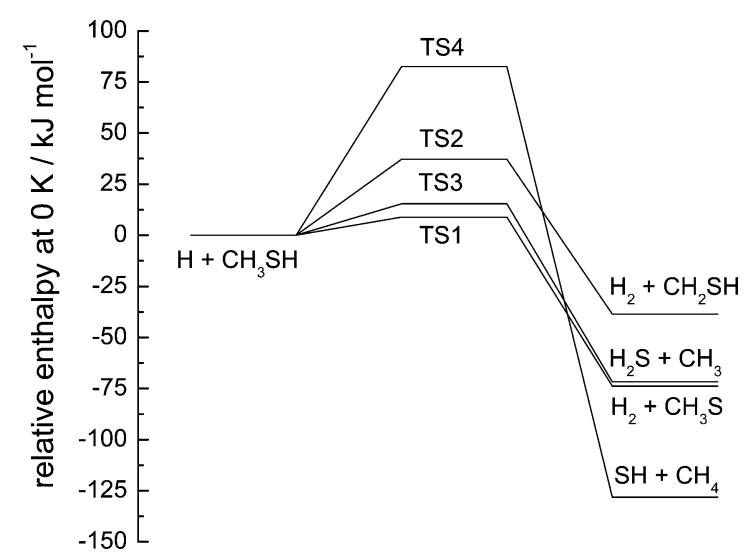

Figure 4. Potential energy diagram for $\mathrm{H}+\mathrm{CH}_{3} \mathrm{SH}$ based on modified W1U theory (see text).

4.2. Simple Kinetic Analysis. Simply looking at the barriers suggests that channels R1.2 and R1.4 will make only small contributions to the overall rate constant $k$, and that channels $\mathrm{R} 1.1$ to R1.3 will be the two dominant pathways. Amano et al. ${ }^{5}$ focused their mass spectrometric experiments on these latter two pathways and obtained $k_{1}=4.8 \times 10^{-11} \mathrm{~cm}^{3}$ molecule $^{-1}$ $\mathrm{s}^{-1} \exp \left(-10.9 \mathrm{~kJ} \mathrm{~mol}^{-1} / R T\right)$ and $k_{3}=1.15 \times 10^{-11} \mathrm{~cm}^{3}$ molecule $\mathrm{s}^{-1} \exp \left(-7.0 \mathrm{~kJ} \mathrm{~mol}^{-1} / R T\right)$. For a quantitative comparison we evaluate canonical variational transition state theory (usually abbreviated to CVT) ${ }^{32}$ for the four channels over 200-3000 K, using the implementation of Truhlar and coworkers in POLYRATE. ${ }^{33}$ The CVT calculations also account for the effects of multidimensional tunneling on the rate constants for channels R1.1-R1.4 via the small curvature tunneling (SCT) approximation. ${ }^{34}$ Reaction coordinates were characterized using QCISD/6-311G $(\mathrm{d}, \mathrm{p})$ theory and the resulting classical barriers (i.e., exclusive of zero-point vibrational energy) were scaled to match the modified W1U values with zero point energy stripped out. GAUSSRATE was used to interface with the GaUSSIAN code to execute $a b$ initio computations in the course of each kinetic run. ${ }^{35}$ The methodology is detailed elsewhere; ${ }^{33}$ here we provide the input files in the Supporting Information to enable reproduction of the CVT/SCT analysis. These calculations relied on all the normal modes being treated as harmonic oscillators. Of course, methanethiol and the transition states contain methyl rotors.

4.3. Roles of Anharmonicity and Symmetry. We developed a torsion correction factor $\tau^{\mathrm{F}}$ to take into account the effects of anharmonicity in modes like the internal rotors, where the harmonic oscillator model will give unrealistic partition functions. First, the energy changes along each torsional mode were evaluated using relaxed scans (i.e., the rest of the geometry was allowed to reoptimize) as a function of torsion angle, at the QCISD/6-311G $(\mathrm{d}, \mathrm{p})$ level of theory. For the bimolecular transition states the lengths of the forming and breaking bonds were held fixed in this exercise. The results are shown in Figure 5. To discuss methanethiol as an example, a straightforward treatment might be to recognize the three symmetrical minima with an internal rotation symmetry number $\sigma_{\mathrm{IR}}=3$ and to obtain an approximate potential by assuming a sinusoidal form and fitting to the harmonic frequency at the bottom of the well $\left(v_{\text {tors }}\right), \sigma_{\mathrm{IR}}$ and the moment of inertia for twisting (assumed not to change significantly during torsion). This latter quantity was obtained with the MOMINERT algorithm within the MULTWELL suite of Barker and co-workers. ${ }^{36}$ Figure 5a shows this would be a reasonable procedure for methanethiol. The torsional potential also controls the reaction path degeneracy, which we denote as RPD. This has been carefully discussed elsewhere, ${ }^{37,38}$ with the conclusion that RPD $=m^{\dagger} \sigma /$ $m \sigma^{\dagger}$. For a given species, $\sigma$ is the product of the overall rotational symmetry number (obtained easily via group theory) and the internal rotation symmetry number (which is not always obvious; complications can arise if there are wells are of different depths), $\dagger$ denotes a transition state rather than reactant property, and $m$ is the number of optical isomers if the species is chiral. Two limiting cases for developing partition functions of torsions can be identified. If the barrier is very high (relative to $k_{\mathrm{B}} T$ ), then the system's behavior tends toward that of a set of $\sigma_{\mathrm{IR}}$ harmonic oscillators. If there are no barriers (and no minima), then a free rotor partition function can be defined analytically as $\left(\pi k_{\mathrm{B}} T / h B\right)^{1 / 2}$ (with the moment of inertia $\mathrm{B}$ in $\mathrm{Hz}$ ), which does not include a $\sigma_{\mathrm{IR}}$ factor. Of course many systems, including all those here, fall in between. In some cases a species is chiral, and its enantiomers may be interconvertable by a torsion or a bend. In the former case, two distinct enantiomers may contribute to the count of $\sigma_{\mathrm{IR}}$. If the bending frequency is high, then there are two distinguishable harmonic oscillators, accounted for by $m=2$, and if it corresponds to a transition state, then the reaction flux passes independently through one transition state and its mirror image. In the limit as the separating barrier tends to zero, we effectively tend toward a single structure.

Questions can arise such as what are the appropriate values of $m$ and $\sigma_{\mathrm{IR}}$ and where do these variables "go" as $k_{\mathrm{B}} T$ becomes larger than the barriers to torsion or bending? Sophisticated methods exist to address these issues, and we have recently applied an example, the MS-T approach of Truhlar and coworkers, ${ }^{39}$ to the behavior of $\mathrm{N}_{2} \mathrm{O}_{5}$, which contains two coupled internal rotors. ${ }^{40}$ However, the systems here are simpler and contain a single torsion that we assume is separable from the other motions of the molecules. We explore the direct numerical solution of the Schrödinger equation for the anharmonic modes with the help of the FGH program, ${ }^{41}$ and from the energy levels obtained, $\varepsilon_{\mathrm{j}}$, deduce the anharmonic partition $q_{\mathrm{anh}}$ by direct summation of the Boltzmann terms, $q_{\text {anh }}=\Sigma \exp \left(-\varepsilon_{\mathrm{i}} / k_{\mathrm{B}} T\right)$. We defined our zero such that $\varepsilon_{0}=0$. This procedure naturally accounts for the number of minima, whether they are equally deep or not, and whether levels are split significantly by tunneling, and it does not require an analytic form of the potential. We interpolated 240 points, with a spline fit, for the potentials shown in Figure 5, and computed the first 80 eigenvalues $\varepsilon_{\mathrm{i}}$. As may be seen, most species have a simple potential like that for methanethiol. Typical aspects are that bound levels near the bottom of the well are almost triply degenerate (they are split by a few wavenumbers because of mixing via tunneling between the minima), there is complex behavior at energies around the top of the barrier, and at high energies quasi-degenerate pairs of energy levels are found, which 
(a)
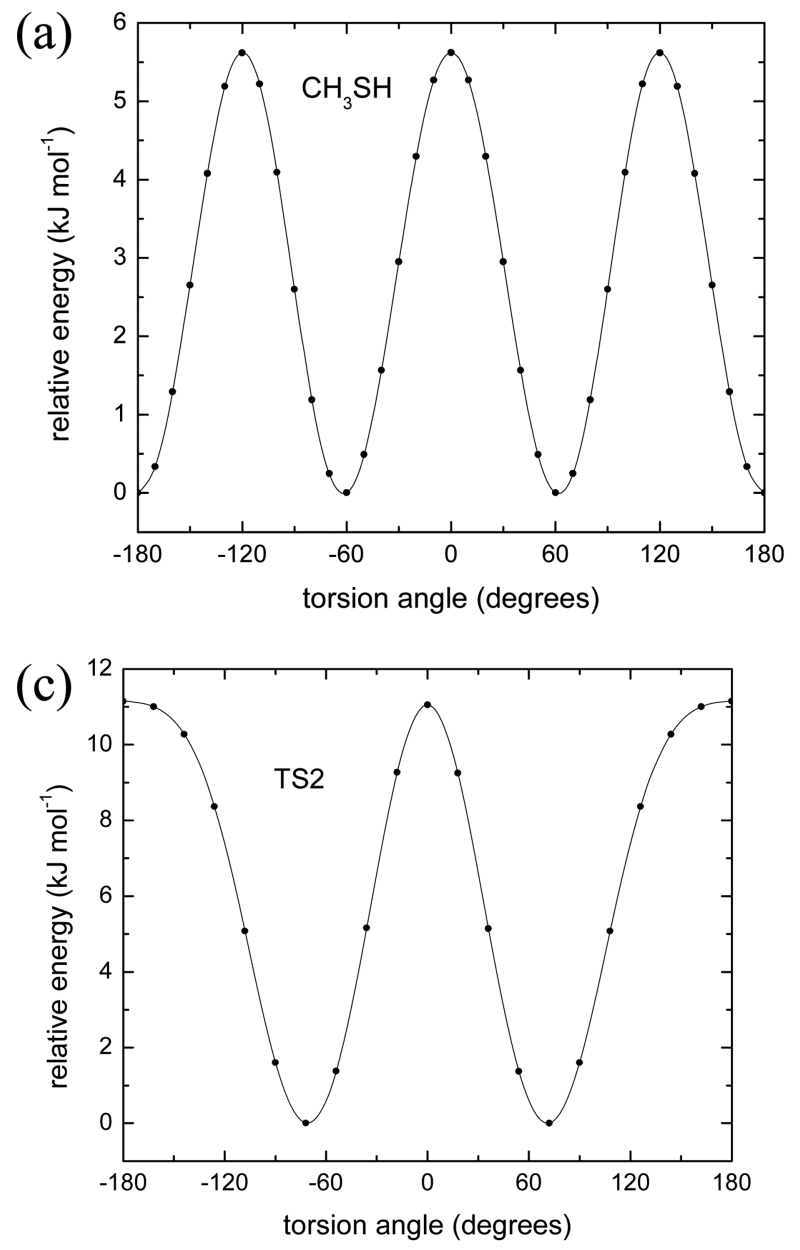

(e)

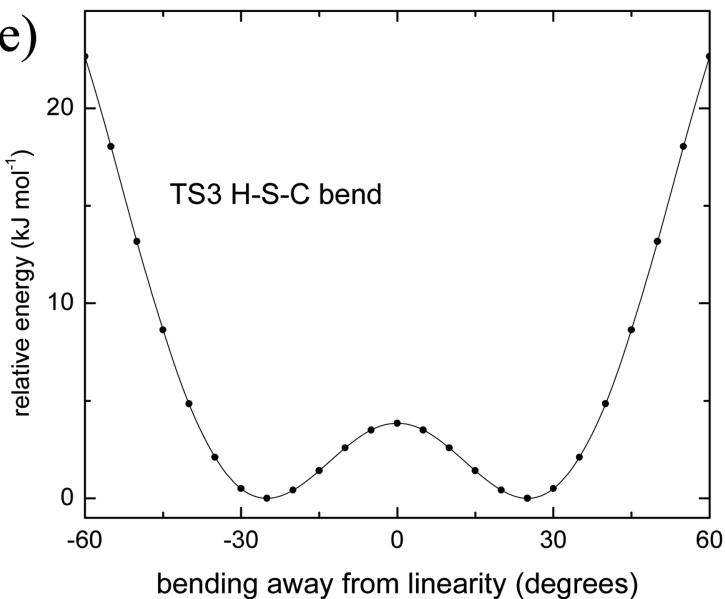

(b)

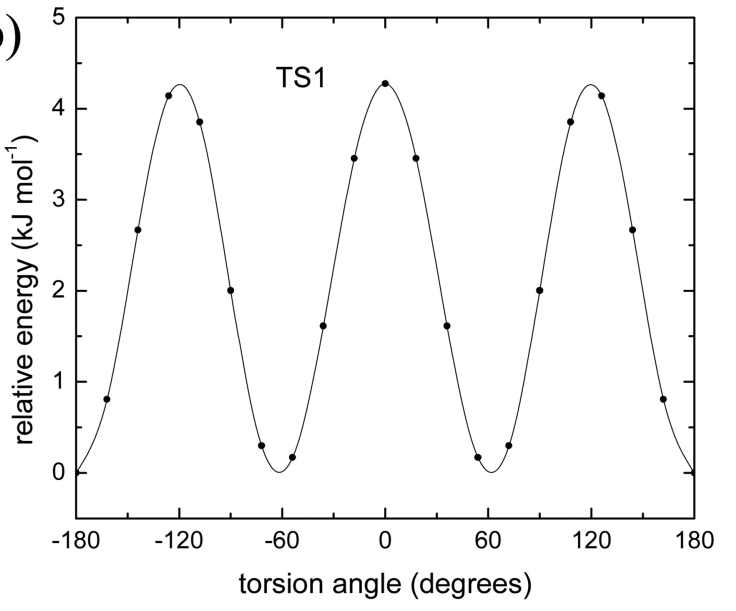

(d)

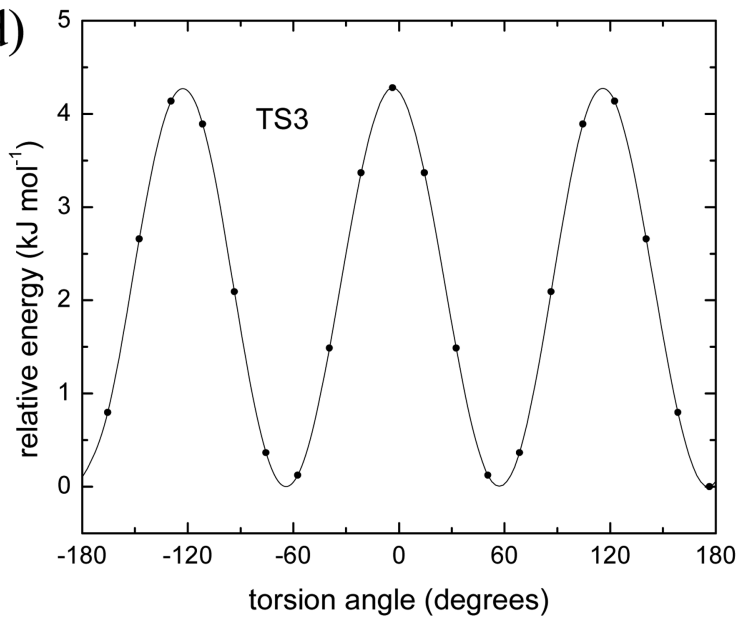

(f)

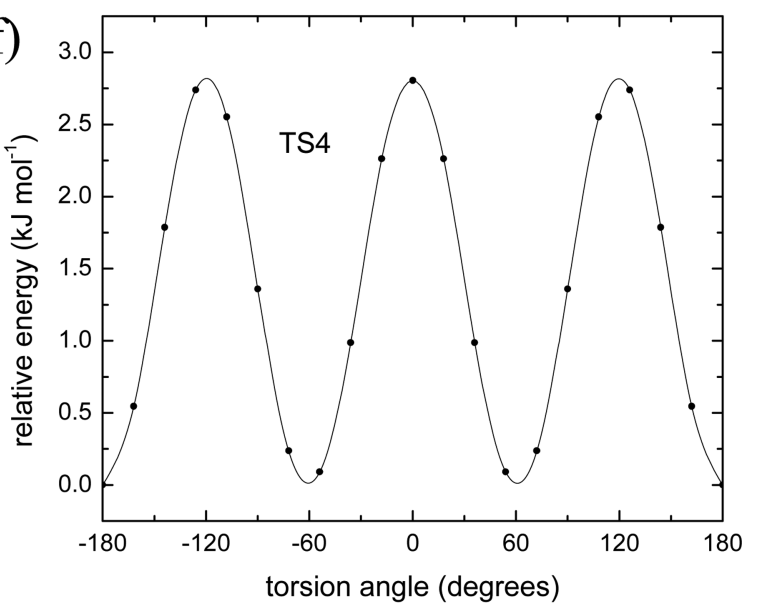

Figure 5. Anharmonic potentials from relaxed scans at the QCISD/6-311G(d,p) level of theory: (a) C-S torsion in methanethiol, (b) C-S torsion in TS1; (c) C-S torsion in TS2; (d) C-S torsion in TS3; (e) H-S-C bending in TS3; (f) C-S torsion in TS4.

correspond to positive and negative angular momentum for free rotor states. Because the lower levels have $\varepsilon$ comparable to $k_{\mathrm{B}} T$, the overall free rotor partition function is not a good approximation until very high temperatures in our system.

4.4. Kinetic Results. Given that the underlying CVT/SCT rate constant calculations were performed with all modes treated as harmonic vibrations, we multiply the rate constant by a factor $\tau^{\mathrm{F}}(\mathrm{TS}) / \tau^{\mathrm{F}}$ (reactant), which allows both for anhamonicity and the reaction path degeneracy and for transition between the limiting cases noted above. $\tau^{\mathrm{F}}$ is defined as $q_{\mathrm{anh}} / q_{\mathrm{harm}}$, where $q_{\mathrm{harm}}$ is obtained on the same basis as $q_{\mathrm{anh}}$, so here it is (1 $\left.\exp \left(-h v_{\text {tors }} / k_{\mathrm{B}} T\right)\right)^{-1}$. For pathway R1.1, although both $\mathrm{CH}_{3} \mathrm{SH}$ and TS1 showed major deviations from the harmonic oscillator model, these deviations were by similar factors and so mostly cancel when they combine in the final rate constant. Much the same occurs for pathway R1.4 and the torsional contribution to R1.3. TS2 is an example of a chiral species, whose enantiomers interconvert by internal rotation around the $\mathrm{C}-\mathrm{S}$ bond. We had 
initially speculated whether to allow for internal rotational symmetry for each of the two enantiomers; inspection of the corresponding potential in Figure 5 shows this would be a mistake. In fact, similar transition states were encountered in cases involving radical attacks on the methyl group in methanol ${ }^{42-44}$ and, as discussed in those instances, in these situations one must be careful not to double-count the torsional contribution. Because a torsional treatment based on the potential for internal rotation leading to the interconversion between the two distinguishable (nonsuperposable) minima already captures the contributions of each of these, the subsequent inclusion of a chirality factor is superfluous. TS3 is also chiral. We allow for torsion around the $\mathrm{C}-\mathrm{S}$ bond in the usual way, but this torsion does not transform one enantiomer to the other. Instead, this interconversion is accomplished by an $\mathrm{H}-$ $\mathrm{S}-\mathrm{C}$ bending mode. We mapped out part of this double-well potential in Figure 5 and solved for that motion too to arrive at a second $\tau^{\mathrm{F}}$ factor. All the $\tau^{\mathrm{F}}$ results are summarized in Table 3 . The

Table 3. Anharmonicity Correction Factors $\tau^{\mathrm{F}}=q_{\mathrm{anh}} / q_{\mathrm{harm}}$ Computed Directly from the QCISD/6-311G $(d, p)$ Potentials

\begin{tabular}{lcccccc}
\hline $\mathrm{T} / \mathrm{K}$ & $\begin{array}{c}\text { torsion in } \\
\mathrm{CH}_{3} \mathrm{SH}\end{array}$ & $\begin{array}{c}\text { torsion } \\
\text { in TS1 }\end{array}$ & $\begin{array}{c}\text { torsion } \\
\text { in TS2 }\end{array}$ & $\begin{array}{c}\text { torsion } \\
\text { in TS3 }\end{array}$ & $\begin{array}{c}\text { bending } \\
\text { in TS3 }\end{array}$ & $\begin{array}{c}\text { torsion } \\
\text { in TS4 }\end{array}$ \\
200 & 3.15 & 3.18 & 2.06 & 3.24 & 2.02 & 3.31 \\
250 & 3.23 & 3.21 & 2.10 & 3.30 & 2.07 & 3.31 \\
298.15 & 3.29 & 3.22 & 2.14 & 3.32 & 2.10 & 3.27 \\
300 & 3.29 & 3.22 & 2.14 & 3.32 & 2.10 & 3.27 \\
400 & 3.33 & 3.18 & 2.23 & 3.31 & 2.12 & 3.16 \\
600 & 3.29 & 3.02 & 2.38 & 3.16 & 2.10 & 2.91 \\
800 & 3.17 & 2.84 & 2.46 & 2.99 & 2.04 & 2.68 \\
1000 & 3.04 & 2.68 & 2.49 & 2.83 & 1.96 & 2.50 \\
1200 & 2.91 & 2.54 & 2.49 & 2.68 & 1.88 & 2.34 \\
1500 & 2.74 & 2.35 & 2.45 & 2.49 & 1.76 & 2.15 \\
1800 & 2.59 & 2.20 & 2.39 & 2.34 & 1.64 & 2.00 \\
2000 & 2.50 & 2.12 & 2.35 & 2.25 & 1.57 & 1.92 \\
2400 & 2.34 & 1.97 & 2.27 & 2.10 & 1.43 & 1.78 \\
3000 & 2.15 & 1.80 & 2.14 & 1.91 & 1.27 & 1.61 \\
\hline
\end{tabular}

CVT/SCT kinetic results are listed in Table 4, and summaries in the form of modified Arrhenius expressions (of the form $k=$ $\left.A T^{n} \exp (-B / T)\right)$ are provided in Table 5. These are shown graphically on Figure 6.

This figure illustrates some of the limitations of our kinetic analysis. Perhaps the most striking aspect is that all the theoretical lines are distinctly curved, with $n$ for the two dominant channels in the range $1-2$, as would be expected on the basis of the likely temperature dependence of the partition functions. ${ }^{45}$ By contrast, the combined experimental data set over 250-1000 $\mathrm{K}$ clearly is consistent with $n$ near 0 . This must limit the possibilities for any close agreement between theory and experiment.

Considering initially the overall rate constant, we can see that the behavior of eq 3 is reproduced to within a factor of 3 or better. At first sight this might be called "good", although systematic deviations are apparent. At temperatures above the Pauling point of around $650 \mathrm{~K}, \mathrm{CVT} / \mathrm{SCT}$ yields $k$ that is too high and has a local activation energy (defined via the slope) that is too high. By contrast, at below around $500 \mathrm{~K} \mathrm{CVT/SCT}$ is low by roughly a factor of 2 . One hopes that a more sophisticated analysis could resolve some of these discrepancies. If the experimental data were available only over a small range of temperature, the strategies of further scaling the transition state frequencies (which affects the extent of looseness in the TS, i.e., the entropy and thus the preexponential $A$ factor) and/or correcting the TS energy (i.e., altering the slope of the Arrheius plot) could be applied to reduce discrepancies between theory and experiment. However, with our new measurements spanning a wide range of $1 / T$, improving the fit at one end of the range worsens the accord at the other. We speculate that more complex factors, such as the extent of quantum mechanical tunneling, may need to be considered in greater depth.

There are significant disagreements concerning the product branching ratios. Along with Wang et al., ${ }^{13}$ we find a major role for channel R1.1 ( $\mathrm{H}$ abstraction from the $\mathrm{SH}$ group) and a small role for channel R1.3 (formation of $\mathrm{CH}_{3}+\mathrm{H}_{2} \mathrm{~S}$ ). At 298 and $1000 \mathrm{~K}$ our CVTST yields $95 \%$ and $81 \%$, respectively, for the contribution of channel R1.1. At $1000 \mathrm{~K}$ there is an $18 \%$ contribution by channel R1.3 and a $1.5 \%$ contribution from channel $\mathrm{R} 1.2$ ( $\mathrm{H}$ abstraction from the $\mathrm{CH}_{3}$ group), whereas channel R1.4 (formation of $\mathrm{SH}+\mathrm{CH}_{4}$ ) is negligible (0.5\%) even at $2000 \mathrm{~K}$. By contrast, the experiments by Amano et al. ${ }^{5}$ yielded much larger branching ratios of $52 \%$ and $40 \%$ for channel R1.3 at 313 and $454 \mathrm{~K}$, respectively. Further experiments might help to resolve this disagreement. We note that if the computed barrier heights were allowed to vary by, e.g., around $1 \mathrm{kcal} \mathrm{mol}^{-1}$, then there would be a significant impact on the computed branching ratios, potentially of the order of a factor of 4 at $400 \mathrm{~K}$. However, the errors in the computed reaction enthalpies shown in Table 1,

Table 4. Rate Constants for $\mathrm{H}+\mathrm{CH}_{3} \mathrm{SH}$ Obtained via SCT/CVTST Theory with Corrections for Anharmonicity

\begin{tabular}{|c|c|c|c|c|c|}
\hline$T / \mathrm{K}$ & $k_{1}$ & $k_{2}$ & $k_{3}$ & $k_{4}$ & total $k$ \\
\hline 200 & $1.84 \times 10^{-13}$ & $5.85 \times 10^{-19}$ & $2.06 \times 10^{-15}$ & $6.04 \times 10^{-28}$ & $1.86 \times 10^{-13}$ \\
\hline 250 & $4.41 \times 10^{-13}$ & $6.11 \times 10^{-18}$ & $1.23 \times 10^{-14}$ & $3.30 \times 10^{-26}$ & $4.53 \times 10^{-13}$ \\
\hline 298.15 & $8.29 \times 10^{-13}$ & $3.72 \times 10^{-17}$ & $4.03 \times 10^{-14}$ & $1.78 \times 10^{-24}$ & $8.69 \times 10^{-13}$ \\
\hline 300 & $8.47 \times 10^{-13}$ & $3.95 \times 10^{-17}$ & $4.19 \times 10^{-14}$ & $2.07 \times 10^{-24}$ & $8.88 \times 10^{-13}$ \\
\hline 400 & $2.13 \times 10^{-12}$ & $6.02 \times 10^{-16}$ & $2.01 \times 10^{-13}$ & $1.62 \times 10^{-21}$ & $2.34 \times 10^{-12}$ \\
\hline 600 & $6.47 \times 10^{-12}$ & $1.58 \times 10^{-14}$ & $1.06 \times 10^{-12}$ & $3.28 \times 10^{-18}$ & $7.54 \times 10^{-12}$ \\
\hline 800 & $1.29 \times 10^{-11}$ & $1.10 \times 10^{-13}$ & $2.60 \times 10^{-12}$ & $1.95 \times 10^{-16}$ & $1.56 \times 10^{-11}$ \\
\hline 1000 & $2.14 \times 10^{-11}$ & $4.05 \times 10^{-13}$ & $4.65 \times 10^{-12}$ & $2.53 \times 10^{-15}$ & $2.65 \times 10^{-11}$ \\
\hline 1200 & $3.20 \times 10^{-11}$ & $1.06 \times 10^{-12}$ & $7.04 \times 10^{-12}$ & $1.48 \times 10^{-14}$ & $4.01 \times 10^{-11}$ \\
\hline 1500 & $5.13 \times 10^{-11}$ & $3.02 \times 10^{-12}$ & $1.10 \times 10^{-11}$ & $9.33 \times 10^{-14}$ & $6.54 \times 10^{-11}$ \\
\hline 1800 & $7.46 \times 10^{-11}$ & $6.50 \times 10^{-12}$ & $1.51 \times 10^{-11}$ & $3.35 \times 10^{-13}$ & $9.66 \times 10^{-11}$ \\
\hline 2000 & $9.22 \times 10^{-11}$ & $9.81 \times 10^{-12}$ & $1.79 \times 10^{-11}$ & $6.49 \times 10^{-13}$ & $1.21 \times 10^{-10}$ \\
\hline 2400 & $1.32 \times 10^{-10}$ & $1.90 \times 10^{-11}$ & $2.34 \times 10^{-11}$ & $1.82 \times 10^{-12}$ & $1.76 \times 10^{-10}$ \\
\hline 3000 & $2.01 \times 10^{-10}$ & $3.93 \times 10^{-11}$ & $3.14 \times 10^{-11}$ & $5.39 \times 10^{-12}$ & $2.77 \times 10^{-10}$ \\
\hline
\end{tabular}


Table 5. Summary of Computed Kinetics in Modified Arrhenius Form, $k=A(T / \mathrm{K})^{n} \exp (-B \mathrm{~K} / T) \mathrm{cm}^{3} \mathrm{molecule}^{-1} \mathrm{~s}^{-1}$

\begin{tabular}{|c|c|c|c|c|}
\hline reaction & $A$ & $n$ & $B$ & valid $T$ range $/ \mathrm{K}$ \\
\hline $\mathrm{H}+\mathrm{CH}_{3} \mathrm{SH} \rightarrow \mathrm{H}_{2}+\mathrm{CH}_{3} \mathrm{~S}(1)$ & $2.30 \times 10^{-16}$ & 1.729 & 496 & $200-3000$ \\
\hline $\mathrm{H}+\mathrm{CH}_{3} \mathrm{SH} \rightarrow \mathrm{H}_{2}+\mathrm{CH}_{2} \mathrm{SH}(2)$ & $6.91 \times 10^{-21}$ & 2.925 & 2389 & $250-3000$ \\
\hline $\mathrm{H}+\mathrm{CH}_{3} \mathrm{SH} \rightarrow \mathrm{CH}_{3}+\mathrm{H}_{2} \mathrm{~S}$ (3) & $1.19 \times 10^{-13}$ & 0.766 & 1623 & $200-3000$ \\
\hline $\mathrm{H}+\mathrm{CH}_{3} \mathrm{SH} \rightarrow \mathrm{CH}_{4}+\mathrm{SH}(4)$ & $1.16 \times 10^{-17}$ & 1.983 & 8321 & $400-3000$ \\
\hline $\mathrm{H}+\mathrm{CH}_{3} \mathrm{SH} \rightarrow$ products & $1.49 \times 10^{-16}$ & 1.824 & 509 & $200-3000$ \\
\hline
\end{tabular}

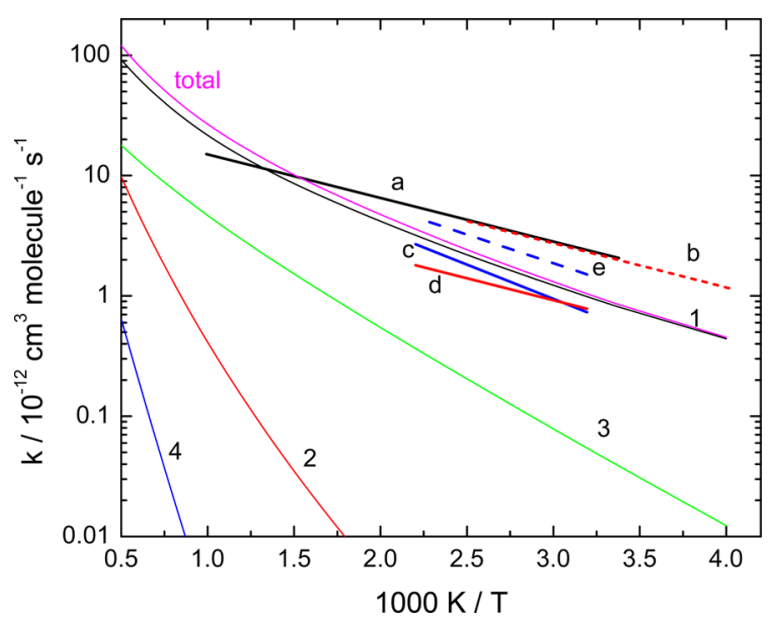

Figure 6. Arrhenius plot of rate constants for $\mathrm{H}+\mathrm{CH}_{3} \mathrm{SH}$. Experimental data are shown in heavy lines and transition state theory results in narrow lines. The labels $1-4$ refer to channels R1.1-R1.4, and "total" is the overall rate constant. Experimental data are (a) this work, total; (b) ref 4, total; (c) ref 5 for channel R1.1; (d) ref 5 for channel R1.3; (e) ref 5 , combined.

of up to $1 \mathrm{~kJ} \mathrm{~mol}^{-1}$, are consistent with the idea of subkcal mol ${ }^{-1}$ accuracy for the saddle points too.

\section{CONCLUSIONS}

The Arrhenius relation determined by Wine et al. for the overall rate constant of $\mathrm{H}+\mathrm{CH}_{3} \mathrm{SH}$ is found to extend to $\sim 1000 \mathrm{~K}$. Four exothermic product channels have been characterized via $a b$ initio methods. The thermochemistry is well-reproduced and the magnitude of the overall rate constant is computed to within about a factor of 2 with canonical variational transition state theory, the small-curvature tunneling model and a detailed treatment of certain anharmonic modes. The channel leading to $\mathrm{H}_{2}+\mathrm{CH}_{3} \mathrm{~S}$ is predicted to be the dominant pathway, by contrast to the study by Amano et al., who found roughly equal branching to $\mathrm{CH}_{3}+\mathrm{H}_{2} \mathrm{~S}$.

\section{ASSOCIATED CONTENT}

\section{S Supporting Information}

Complete geometrical parameters, modified W1U energies, and vibrational frequencies for the reactants, transition states, and products for reactions R1.1-R1.4 optimized at the QCISD/6$311 \mathrm{G}(\mathrm{d}, \mathrm{p})$ level of theory, and input data for transition state theory. This material is available free of charge via the Internet at http://pubs.acs.org.

\section{AUTHOR INFORMATION}

\section{Corresponding Author}

*P. Marshall. E-mail: marshall@unt.edu.

Notes

The authors declare no competing financial interest.

\section{ACKNOWLEDGMENTS}

We thank Prof. Peter Glarborg (Denmark Technical University) for valuable discussions and the National Science Foundation (Grant CBET-0756144) and the R. A. Welch Foundation (Grant B-1174) for support. Computer facilities were purchased in part with NSF Grant CHE-0741936.

\section{REFERENCES}

(1) Bates, T. S.; Lamb, B. K.; Guenther, A.; Dignon, J.; Stoiber, R. E. Sulfur Emissions to the Atmosphere from Natural Sources. J. Atm. Chem. 1992, 14, 315-337.

(2) Gargurevich, I. A. Hydrogen Sulfide Combustion: Relevant Issues under Claus Furnace Conditions. Ind. Eng. Chem. Res. 2005, 44, 77067729.

(3) Petherbridge, J. R.; May, P. W.; Shallcross, D. E.; Harvey, J. N.; Fuge, G. M.; Rosser, K. N.; Ashfold, M. N. R. Simulation of H-C-S Containing Gas Mixtures Relevant to Diamond Chemical Vapor Deposition. Diamond Relat. Mater. 2003, 12, 2178-2185.

(4) Wine, P. H.; Nicovich, J. M.; Hynes, A. J.; Wells, J. R. $\mathrm{CH}_{3} \mathrm{SH}$ Photolysis at $248 \mathrm{~nm}$. Hydrogen Atom Yield and Rate Constant for the $\mathrm{H}+\mathrm{CH}_{3} \mathrm{SH}$ Reaction. J. Phys. Chem. 1986, 90, 4033-4037.

(5) Amano, A.; Yamada, M.; Hashimoto, K.; Sugiura, K. Kinetic Feature of the Reaction Between Methanethiol and Hydrogen Atoms. Nippon Kagaku Kaishi 1983, 3, 385-393.

(6) Vaghjiani, G. L.; Ravishankara, A. R. Photodissociation of $\mathrm{H}_{2} \mathrm{O}_{2}$ and $\mathrm{CH}_{3} \mathrm{OOH}$ at $248 \mathrm{~nm}$ and $298 \mathrm{~K}$ : Quantum Yields for $\mathrm{OH}, \mathrm{O}\left({ }^{3} \mathrm{P}\right)$ and $\left.\mathrm{H}^{2} \mathrm{~S}\right)$. J. Chem. Phys. 1990, 92, 996-1003.

(7) Martin, D.; Jourdain, J. L.; Le Bras, G. Kinetics and Mechanism for the Reactions of $\mathrm{H}$ Atoms with $\mathrm{CH}_{3} \mathrm{SH}$ and $\mathrm{C}_{2} \mathrm{H}_{5} \mathrm{SH}$. Int. J. Chem. Kinet. 1988, 20, 897-907.

(8) Balla, R. J.; Heicklen, J. Oxidation of Sulfur Compounds. IV. The Photo-Oxidation of $\mathrm{CH}_{3} \mathrm{SH}$. J. Photochem. 1985, 29, 311-332.

(9) Balla, R. J.; Heicklen, J. Oxidation of Sulfur Compounds. I. The Photolysis of $\mathrm{CH}_{3} \mathrm{SH}$ and $\left(\mathrm{CH}_{3} \mathrm{~S}\right)_{2}$ in the Presence of NO. Can. J. Chem. 1984, 62, 162-170.

(10) Ruscic, B. Active Thermochemical Tables, version 1.112; Argonne National Laboratory: Lemont, IL, http://atct.anl.gov (accessed Aug 14, 2014).

(11) NIST Computational Chemistry Comparison and Benchmark Database, Release 16a; Johnson, R. D., III, Ed.; 2013; http://cccbdb. nist.gov/.

(12) Peebles, L. R; Marshall, P. High-Accuracy Coupled-Cluster Computations of Bond Dissociation Energies in $\mathrm{SH}, \mathrm{H}_{2} \mathrm{~S}$ and $\mathrm{H}_{2} \mathrm{O}$. J. Chem. Phys. 2002, 117, 3132-3138.

(13) Wang, Y.-X.; Duan, X.-M.; Wang, Q.; Liu, J.-Y. Direct Ab Initio Dynamics on the Reaction of Methanethiol and Hydrogen Atom. Acta Phys. Chim. Sin. 2010, 26, 183-187.

(14) Barnes, E. C.; Petersson, G. A.; Montgomery, J. A., Jr.; Frisch, M. J.; Martin, J. M. L. Unrestricted Coupled Cluster and Brueckner Doubles Variations of W1 Theory. J. Chem. Theory Comput. 2009, 5, 2687-2693.

(15) Karan, K.; Behie, L. A. CS $_{2}$ Formation in the Claus Reaction Furnace: A Kinetic Study of Methane-Sulfur and Methane-Hydrogen Sulfide Reactions. Ind. Eng. Chem. Res. 2004, 43, 3304-3313.

(16) Selim, H.; Al Shoaibi, A.; Gupta, A. K. Fate of Sulfur with $\mathrm{H}_{2} \mathrm{~S}$ Injection in Methane/Air Flames. Appl. Energy 2012, 92, 57-64.

(17) Bongartz, D.; Ghoniem, A. F. Chemical Kinetics Mechanism for Oxy-Fuel Combustion of Mixtures of Hydrogen Sulfide and Methane. Combust. Flame 2015, 162, 544-553. 
(18) Ding, L.; Marshall, P. Kinetic Studies of the Reactions of Atomic Chlorine and Bromine with Silane. J. Phys. Chem. 1992, 96, 2197-2201.

(19) Goumri, A.; Laakso, D.; Rocha, J.-D. R.; Francis, E.; Marshall, P. An Investigation of the Gas-Phase Kinetics of the Reaction $\mathrm{K}+\mathrm{SO}_{2}+\mathrm{Ar}$. J. Phys. Chem. 1993, 97, 5295-5297.

(20) Alecu, I. M.; Gao, Y.; Hsieh, P.-C.; Sand, J. P.; Ors, A.; McLeod, A.; Marshall, P. Studies of the Kinetics and Thermochemistry of the Forward and Reverse Reaction $\mathrm{Cl}+\mathrm{C}_{6} \mathrm{H}_{6}=\mathrm{HCl}+\mathrm{C}_{6} \mathrm{H}_{5}$. J. Phys. Chem. A 2007, 111, 3970-3976.

(21) Peng, J.; Hu, X.; Marshall, P. Experimental and ab Initio Investigations of the Kinetics of the Reaction of $\mathrm{H}$ Atoms with $\mathrm{H}_{2} \mathrm{~S}$. J. Phys. Chem. A 1999, 103, 5307-5311.

(22) Gao, Y.; DeYonker, N. J.; Garrett, E. C.; Wilson, A. K.; Cundari, T. R.; Marshall, P. Enthalpy of Formation of the Cyclohexadienyl Radical and the $\mathrm{C}-\mathrm{H}$ Bond Enthalpy of 1,4-Cyclohexadiene: An Experimental and Computational Re-Evaluation. J. Phys. Chem. A 2009, 113, 69556963.

(23) Benson, S. W. Thermochemistry and Kinetics of SulfurContaining Molecules and Radicals. Chem. Rev. 1977, 78, 23-35.

(24) Bridges, L.; White, J. M. Photochemistry of Methanethiol at 254 and $214 \mathrm{~nm}$. J. Phys. Chem. 1973, 77, 295-298.

(25) Chen, F. Z.; Judge, D. L.; Wu, C. Y. R.; Caldwell, J. Low and Room Temperature Photoabsorption Cross Sections of $\mathrm{NH}_{3}$ in the UV Region. Planetary Space Sci. 1998, 47, 261-266.

(26) Barone, S. B.; Turnipseed, A. A.; Gierczak, T.; Ravishankara, A. R. Quantum Yields of $\left.\mathrm{H}^{2} \mathrm{~S}\right)$ and $\mathrm{CH}_{3} \mathrm{~S}\left({ }^{2} \mathrm{E}\right)$ from the Photolysis of Simple Organosulfur Compounds at 193, 222, and 248 nm. J. Phys. Chem. 1994, 98, 11969-11977.

(27) Marshall, P. Method for Analyzing Exponential Decays. Comput. Chem. 1987, 11, 219-221.

(28) Marshall, P. Errata. Comput. Chem. 1989, 13, 103.

(29) McLean, A. D.; Chandler, G. S. Contracted Gaussian-Basis Sets for Molecular Calculations. 1. 2nd Row Atoms, $\mathrm{Z}=11-18$. J. Chem. Phys. 1980, 72, 5639-5648.

(30) Hehre, W. J.; Radom, L.; Schleyer, P. v. R.; Pople, J. A. Ab Initio Molecular Orbital Theory; Wiley: New York, 1986.

(31) Frisch, M. J.; Trucks, G. W.; Schlegel, H. B.; Scuseria, G. E.; Robb, M. A.; Cheeseman, J. R.; Scalmani, G.; Barone, V.; Mennucci, B.; Petersson, G. A.; et al. Gaussian 09; Gaussian Inc.: Wallingford, CT, 2009.

(32) Garrett, B. C.; Truhlar, D. G. Variational Transition-State Theory. Acc. Chem. Res. 1980, 13, 440-448.

(33) Zheng, J.; Zhang, S.; Lynch, B. J.; Corchado, J. C.; Chuang, Y.-Y.; Fast, P. L.; Hu, W.-P.; Liu, Y.-P.; Lynch, G. C.; Nguyen, K. A.; et al. POLYRATE: Computer Program for the Calculation of Chemical Rates for Polyatomics, version 2010-A; University of Minnesota: Minneapolis, MN, 2010.

(34) Liu, Y.-P.; Lynch, G. C.; Truong, T. N.; Lu, D.-h.; Truhlar, D. G. Molecular Modeling of the Kinetic Isotope Effect for the $[1,5]$ Sigmatropic Rearrangement of cis-1,3-Pentadiene. J. Am. Chem. Soc. 1993, 115, 2408-2415.

(35) Zheng, J.; Zhang, S.; Corchado, J. C.; Chuang, Y.-Y.; Coitino, E. L.; Ellingson, B. A.; Truhlar, D. G. GAUSSRATE, version 2009-A; University of Minnesota: Minneapolis, MN, 2009.

(36) Barker, J. R.; Ortiz, N. F.; Preses, J. M.; Lohr, L. L.; Maranzana, A.; Stimac, P. J.; Nguyen, L. T.; Kumar, T. J. D. MultiWell-2014.1, 2014, http://aoss-research.engin.umich.edu/multiwell/.

(37) Gilbert, R. G.; Smith, S. C. Theory of Unimolecular and Recombination Reactions; Oxford University Press: Oxford, U.K., 1990.

(38) Fernandez-Ramos, A.; Ellingson, B. A.; Meana-Paneda, R.; Marques, J.; Truhlar, D. G. Symmetry Numbers and Chemical Reaction Rates. Theor. Chem. Acc. 2007, 118, 813-826.

(39) Zheng, J.; Yu, T.; Papajak, E.; Alecu, I. M.; Mielke, S. L.; Truhlar, D. G. Practical Methods for Including Torsional Anharmonicity in Thermochemical Calculations on Complex Molecules: The InternalCoordinate Multi-Structural Approximation. Phys. Chem. Chem. Phys. 2011, 13, 10885-10907.
(40) Alecu, I. M.; Marshall, P. Computational Study of the Thermochemistry of $\mathrm{N}_{2} \mathrm{O}_{5}$ and the Kinetics of the Reaction $\mathrm{N}_{2} \mathrm{O}_{5}+$ $\mathrm{H}_{2} \mathrm{O} \rightarrow 2 \mathrm{HNO}_{3}$. J. Phys. Chem. A 2014, 118, 11405-11416.

(41) Johnson, R. D., III. Fourier Grid Hamiltonian 1D Program, ver 1.01 http://www.nist.gov/mml/csd/informatics_research/fourier_ grid_hamiltonian_interface.cfm, 1999.

(42) Chuang, Y.-Y.; Radhakrishnan, M. L.; Fast, P. L.; Cramer, C. J.; Truhlar, D. G. Direct Dynamics for Free Radical Kinetics in Solution: Solvent Effect on the Rate Constant for the Reaction of Methanol with Atomic Hydrogen. J. Phys. Chem. A 1999, 103, 4893-4909.

(43) Meaña-Paneda, R.; Truhlar, D. G.; Fernández-Ramos, A. HighLevel Direct-Dynamics Variational Transition State Theory Calculations Including Multidimensional Tunneling of the Thermal Rate Constants, Branching Ratios, and Kinetic Isotope Effects of the Hydrogen Abstraction Reactions from Methanol by Atomic Hydrogen. J. Chem. Phys. 2011, 134, 094302.

(44) Alecu, I. M.; Truhlar, D. G. Computational Study of the Reactions of Methanol with the Hydroperoxyl and Methyl Radicals. 2. Accurate Thermal Rate Constants. J. Phys. Chem. A 2011, 115, 14599-14611.

(45) Mulcahy, M. F. R. Gas Kinetics; Nelson: London, 1973. 